\title{
AC 2007-160: CURRENT TOPICS IN REHABILITATION ENGINEERING
}

\section{Paul King, Vanderbilt University}

Paul King is a long time member of the engineering faculty at Vanderbilt University. He has an appointment in both Biomedical Engineering and Mechanical Engineering, with past joint appointments in Anesthesiology and Orthopedics and Rehabilitation. His primary area of endeavor is the teaching of design.

\section{Mark Richter, MaxMobility}

Mark Richter is the director of MAX mobility, an assistive technology R\&D company, and an Adjunct Assistant Professor in the Department of Biomedical Engineering at Vanderbilt University. Dr. Richter's research interests include: wheelchair design, propulsion technique, wheelchair setup, adaptive exercise equipment and recreational technologies. He has taught several project-based courses where student teams designed assistive devices for clients with disabilities 


\title{
Current Topics in Rehabilitation Engineering
}

\begin{abstract}
This paper describes a new introductory one hour freshman module developed to cover current topics in Rehabilitation Engineering. The course was team taught by an engineer/owner of a local mobility aids firm and by a biomedical engineering design instructor. Students who enrolled for the course were presented with the following course description: "Rehabilitation engineering is the application of technologies, engineering methodologies or scientific principles to meet the needs of individuals with disabilities in areas that include mobility, communication, education, employment, transportation, independent living, and recreation. We will explore a variety of the current topics in rehabilitation research and development. Engineers from all disciplines contribute to the field of rehabilitation engineering. There are no prerequisites for the course. Career options in this field include research and development, physical rehabilitation medicine, technology development (e.g. wheelchair companies), technology prescription (clinical), and policy development. Course performance will be based on class participation, homework, written reports and oral presentations." Included with the above lectures on special topics was an assistive design project for a child client who was in need of bathroom aids due malformed arms. Three person teams of the students competed for a best solution to the needs of the client. Other individual oral reports critically reviewed papers in the area of Rehabilitation Engineering.
\end{abstract}

\section{Introduction}

One hour "modules" on select topics have been developed at Vanderbilt University in an attempt to increase student retention in the freshman year. Incoming first year students are presented with a list of (generally) ten or so modules that they may choose to elect one or none of. Topics available yearly include Engineering Ethics, Electrocardiogram Capture and Analysis, Engineering Scuba Diving, Moore's Law and Engineering Economics, and the like. Most students $(52 \%)$ opt to take a module.

Co-Author Richter has sponsored and supervised several senior design (and other) projects for three years prior to this academic year. His projects, due to his career, were all related to rehabilitation engineering. His expertise in this area gave rise to the consideration of either a full semester upper level course in rehabilitation engineering or the development of a freshman module in the area. An administrative decision resulted in the request for an introductory module in rehabilitation engineering. As the design course was taught by co-author King, it was suggested that the course be team taught.

A typical lecture module meets for one hour a week for 15 weeks, unless special arrangements are made to double-up on a given class session. The remainder of this paper will discuss the course content and evaluation of the freshman module "Current Topics in Rehabilitation Engineering" as taught in the fall term, 2006.

\section{Course Content}


Twenty students (enrollment cap) signed up for the first offering of the course. The first class period was used to introduce the instructors and the class to each other, and to give an overview of the area of rehabilitation engineering as well as to inform the class as to the course grading structure. Grades were to be determined via graded pre-emptive learning exercises ("PELE", $50 \%$ ), an assistive technology design project (25\%), and a publication review (25\%). The PELE assignments were designed to get the students thinking about the upcoming lecture material prior to the lecture itself. Since the assignments were turned in prior to the start of each class, they also served to encourage attendance. The assistive technology design project was presented as a reallife example of assistive technology application, with its inherent client interaction needs of confidentiality and respect for individual's feelings. The publication review was presented as a means of indicating to students the broadness of the field of rehabilitation engineering, and as an introduction to a more comprehensive review of literature. At the close of class, students participated in a visualization exercise whereby they closed their eyes and imagined they were in a car accident while driving and left paralyzed as a result. The changes to their way of life, such as a loss of independence and altered social interactions were discussed. It was emphasized that persons with disabilities were no different from them. This exercise served to bring the students closer to the role of assistive technology and to break down the barriers of communication with persons with disabilities. Students were then presented with copies of the "Closing the Gap" newsletter to give them a feeling for some of the types of technological interventions they would be seeing during the term.

At the second meeting of the course, the class met student "client M" and his parent. M is a seven year old child who has severe upper limb deformities. He has very shortened forearms with only a thumb and index finger on his left hand. His right hand has no grasping capabilities while his left hand has minimal grasping capabilities but only two fingers. The client's shoulders are fully functional, but his elbows have fixed flexion contractures of over 130 degrees. The goal, as presented to the class, was to help this child become more independent in his everyday life by designing assistive devices to help him pull his pants up and down for toileting and for personal sanitation (extra credit) after bowel movements. Students were put into design teams (5 teams of 3 and 1 team of 4) and implored to interact with the client in order to better understand his needs. The design project was structured as a competition, wherein the winning team would be exempt from the publication review assignment. The teams had 4 weeks to deliver their prototype and complete their design report. The first two sections of their design reports, including the need and brainstorming sections, were due 2 weeks into the project. The students were given unlimited access to the client and encouraged to interact with him during the design process.

The third class meeting covered the technological and human resources available to the individual with disabilities. These included devices available for activities of daily living, computer access, work and home accommodation \& modification, and communication aids. The key speaker was an employee of a technology access center. Several devices were demonstrated, such as sip and puff controls and alternative keyboards.

A fourth class meeting was conducted by an employee of a powered wheelchair company. The seating and positioning process and a demonstration of alternative drive controls were covered in 
a PowerPoint lecture, followed by a demonstration of one of two powered wheelchairs brought to the class. At the end of the period, students were invited to use the chairs. Most were willing to try one or both of the chairs.

The fifth class meeting continued the discussion and demonstration of technological aids, but restricted the scope of the discussion to the uses of switches, toy adaptations, and augmented communication devices. Specifically covered were the steps in training a new (often mentallychallenged) user to control such devices as a powered wheelchair via cause and effect training.

A sixth class period covered wheelchair sports, the modifications of devices and the processes necessary to actively involve the participants (wheelchairs, game rules, etc.). A video of water skiing activities (a senior design project topic) was the highlight of a PowerPoint slide show on the various sports activities that are feasible with device modifications. The presentation was given by a paraplegic athlete.

Two class periods were combined to allow "client M" and his parent to view devices and process that the student groups had designed to assist in pant removal and replacement. Several student groups considered assistive devices such as loops on the client's pants and hooks on his sneakers as a convenient way to remove pants for toileting. Several groups tried to develop pulley type systems to assist in pants replacement after toileting. Each of the designs demonstrated a good (for freshmen) first attempt at a client-specific assistive device. Two student groups attempted the relevant hygiene related concern; both had a reasonable first attempt. An example design attempt may be seen below.

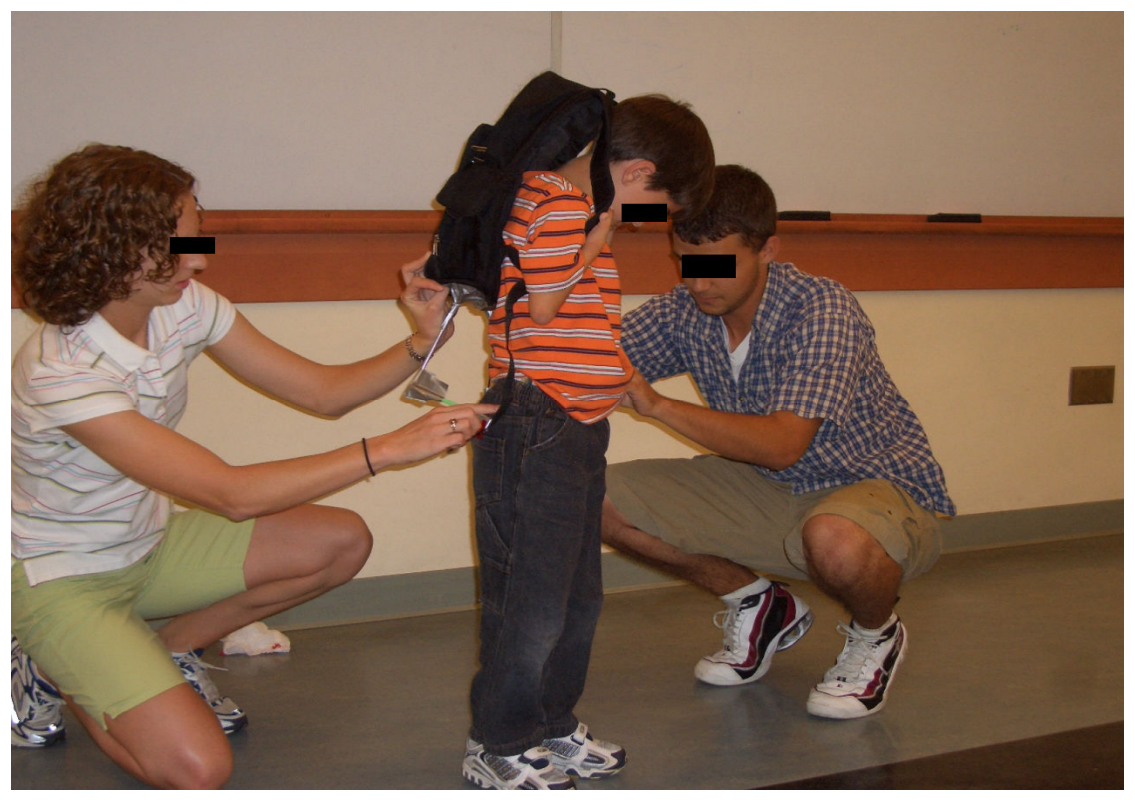

One class period $\left(9^{\text {th }}\right)$ gave the students an overview of the design process. The importance of understanding and defining the design process was illustrated by a hypothetical design problem, where the class became the designers responsible for determining the true problem in a case 
where a pizza shop owner claimed that his workers were suffering from carpal tunnel syndrome due to a bad pizza oven design. A discussion was further held on how to investigate device accidents, most notably a death caused by injection of air from a saline infusion bag into a patient during an exploratory heart examination.

Two potential PhD candidates used the next two class periods $\left(10^{\text {th }}, 11\right.$ th $)$ to cover their proposed dissertation topics. One student in particular described the current state of the art in wheelchair propulsion environments and the measurement of forces and positions involved. A second student gave an overview of the dynamics of wheelchair propulsion, and the metabolic costs of different push patterns, and suggested means to redesign current wheelchairs to minimize the metabolic cost of locomotion.

Two class periods were combined $\left(12^{\text {th }}, 13^{\text {th }}\right)$ to enable the class to individually present their publication reviews. Students individually presented the details of a published journal article related to Rehabilitation Engineering. The articles were randomly assigned and covered a wide range of topics including: wheelchair propulsion, seating and positioning, disability demographics, measurement techniques, dynamic model simulations and exercise modalities. Presentations were limited to 5 minutes, with 2 minutes for questions. Students had 4 weeks to prepare for the assignment, which also included critically reviewing 3 supporting articles that were referenced in their primary article. A 1-2 page (single-spaced) write up on each article was required. Students were provided with their primary article but were required to look-up and acquire their supporting articles from the University Biomedical Library.

Home modification and environmental controls were covered in the $14^{\text {th }}$ lecture by a clinical rehabilitation engineer who routinely provides these services to clients with disabilities. The concept of Universal Design was explored and examples of how it can be applied to home design were given. Space requirements for wheeled mobility were described along with the consequences of not having adequate space to get in or around a room. Accessibility standards defined by the Americans with Disabilities Act (ADA) were explained. Environmental control technologies, such as universal remote control units, were described and demonstrated to the class.

The $15^{\text {th }}$ and last lecture covered lower extremity prosthetics. The lecture was given by a local prosthetist, which was supported by two co-workers and three clients with lower limb amputees (one with bi-lateral prosthetics). The history of prosthetics technology was covered, along with the fitting, training and adjustment processes. The clients shared their experiences using prosthetics and which technologies were their favorites. Students were allowed to try out various below-the-knee prosthetics by using specialized cuffs that held the knee at a 90-degree angle. Students also had the privilege of observing demonstrations of running with prosthetics by each of the clients.

Table one (next) is a summary of the lectures and lecturers used in the class as described above 


\begin{tabular}{|c|l|l|l|}
\hline Class & Topic & Speaker & Profession \\
\hline 1 & Introduction & $\begin{array}{l}\text { M. Richter, PhD, } \\
\text { PE }\end{array}$ & CEO, Max-Mobility, Nashville TN \\
\hline 2 & Design Challenge & Client & Grade school student \\
\hline 3 & Workplace Modification & K. Lilley, MS & Rehab. Eng., Tech. Access Center., TN \\
\hline 4 & Power WC & $\begin{array}{l}\text { A. Eubank, OTR, } \\
\text { ATP }\end{array}$ & Permobil Inc., Lebanon, TN \\
\hline 5 & Augmentation Aids & $\begin{array}{l}\text { K. Lilley, MS, } \\
\text { BME }\end{array}$ & Rehab. Eng., Tech. Access Center., TN \\
\hline 6 & WC Sports & R. Rodriguez, ME & Asst. Prof., TSU \\
\hline $7 \& 8$ & Design Product & students & \\
\hline 9 & Design in BME & P. King, PhD, PE & Assoc. Prof., Vanderbilt U. \\
\hline 10 & Propulsion Measures & K. Wood, ME & Asst. Prof., TSU \\
\hline 11 & Propulsion Dynamics & R. Rodriguez, ME & Asst. Prof., TSU \\
\hline $12 \&$ & Publication Reviews & Students & \\
\hline 13 & & K. Lilley, MS & Rehab. Eng., Tech. Access Center., TN \\
\hline 14 & Home Controls & Aaron Fitzsimmons & Staff, Superior Prosthetics \\
\hline 15 & Prostheses (LE) & &
\end{tabular}

Table 1: Topics and Speakers by Class for Rehabilitation Engineering Module, 2006.

PELE homework assignments were designed to introduce the students to the topics being covered in the upcoming lectures. The assignments generally took less than an hour to complete and were to be done on an individual basis. Since there was no course text book assigned, students were generally given a target web site to visit and a series of questions to answer based on the information that could be found somewhere within that particular web site. Examples of web sites included: the IDEO design corporation (www.ideo.com), the Job Accommodation Network site (www.jan.wvu.edu), and The Family Center on Technology and Disability (www.fctd.info).

\section{Conclusions}

The course was successful with enrollment maxed-out at 20 students. One student chose to discontinue the class, leaving the final enrollment at 19. The small class size was designed to allow for interaction with the client during the assistive technology design challenge as well as to encourage a sense of community among the students.

Course evaluations were largely positive, with some students expressing considerable interest in the field of Rehabilitation Engineering. One student commented that "I liked how various "specialists" came in and talked about their specialties. The class provided great insight into various career options and some non-traditional engineering career paths. Design challenge was a great experience. I liked having the ability to work on a real clinical case as a freshman. The design project provided hands-on experience/insight into what a Rehabilitation Engineering career would entail". Another student commented that "I came into this course knowing absolutely nothing about Rehabilitation Engineering, and this ended up being my favorite class. I looked forward to class each week and enjoyed all of the guest lectures. I hope to take more 
classes throughout my four years at Vanderbilt in the field of Rehabilitation Engineering". Another student has applied for a summer internship in Rehabilitation Engineering at the University of Pittsburgh based on her newfound interest in the field.

One student was so affected by the course that she is now considering career in Rehabilitation Engineering. She wrote "I started out in BME thinking it would be a good Pre-Med track, but because of your class I think I've changed my mind. I wanted to be a doctor because I wanted to help people. And I wanted to be an engineer because I love math and science and, in general, fixing things. But then, when I started to learn about all the different ways to help people with disabilities, I started to think about my cousin. She's only a few months younger than me, and we've always been really close. She has cerebral palsy that largely affects her walking capabilities as well as other fine motor skills... It amazes me how much she can do given her special circumstances, but being in your class showed me that she can do so much more and have so much more independence. I would love to be able to help my cousin and other individuals similar to her and I think working in a field of rehabilitation engineering could really be a good fit for me".

One of the most compelling aspects of this course was the use of professionals who are actively practicing in their particular areas of Rehabilitation Engineering. They brought not only a passion for their work to the lectures but also an assortment of current assistive technology products to demonstrate to the class. The use of actual products as visual aids, (which were generally passed around the class) was very effective at engaging the students in the lecture material. Instructors interested in developing a similar course but lack the contacts in industry are encouraged to contact their local center for independent living or disability support center. From there a string of contacts can be established in a variety of related specialties within Rehabilitation Engineering. Another resource is the Rehabilitation Engineering Society of North America (RESNA) (www.resna.org), which may also be useful in generating contacts for guest lecturers. Individuals who are certified as Assistive Technology Providers (ATP) can be found on the RESNA web site by city and state.

Based on the success of this course, we plan to offer it again in 2007-2008 with the enrollment cap increased to 30 . There will not be any significant changes made to the curriculum. However, a well-suited design project will need to be identified prior to the course start date. We will work with local disability services groups to identify potential candidate projects. We also plan to offer a full three credit hour rehabilitation engineering Junior/Senior elective course in the 2008-2009 school year, which will give students exposure to more advanced topics in the field.

This work was partially supported by the Engineering Research Centers Program of the National Science Foundation under Award Number EEC-9876363. 